\title{
Multiple subpial transection: a review of 21 cases
}

\author{
Inder Mohan S Sawhney, Iain J A Robertson, Charles E Polkey, Colin D Binnie, \\ Robert D C Elwes
}

\begin{abstract}
Multiple subpial transection (MST) is a novel technique in surgery for epilepsy, employed in patients where some or all of the epileptogenic zone cannot be resected because it lies in a vital cortical area. Twenty one patients subjected to MST were reviewed. Eighteen patients had medically intractable epilepsy and three patients had Landau-Kleffiner syndrome. Their ages ranged from 6 to 47 (mean 15.9) and duration of epilepsy ranged from 0.33 to 42 (mean 8.6) years. Preoperative MRI showed focal abnormalities in eight cases. Detailed electrophysiological examination was carried out on all patients. Brain resection was performed in addition to MST in 12 patients. A further six patients underwent brain biopsy. Three patients with Landau-Kleffiner syndrome were subjected neither to resection nor to biopsy. Histopathological examination showed Rasmussen's syndrome in six patients, cortical dysplasia in six, cerebral tumour in one, and non-specific changes in five. Multiple subpial transection was carried out mainly in precentral and postcentral regions.

Eighteen patients have been followed up for one to five years, and three for 10 months. The three patients with LandauKleffiner syndrome were mute before operation and have shown substantial recovery of speech. Of the other 18,11 showed a worthwhile decrease in seizure frequency. None of the patients developed chronic neurological deficits attributable to MST. It is concluded that MST leads to worthwhile seizure control without major neurological deficit in patients who would otherwise be inoperable.
\end{abstract}

(F Neurol Neurosurg Psychiatry 1995;58:344-349)

Keywords: epilepsy surgery; multiple subpial transection; Rasmussen's syndrome; Landau-Kleffner syndrome.

There has been a steady increase during the past decade in the number of patients undergoing surgery for medically intractable seizures. Brain resection is the most common surgical procedure and typically some $58 \%$ of patients undergoing temporal lobe resection become seizure free. ${ }^{1}$ Resection of cortical areas controlling speech, movement, and primary sensation is not feasible, however, as it results in unacceptable neurological deficit. Multiple subpial transection (MST) is a novel technique, conceived and first described by Morrell et $a l^{2}$ and employed in those patients where the epileptogenic lesion cannot be resected because it lies in an eloquent cortical area. ${ }^{2-4}$ The technique consists of severing horizontal intracortical fibres at intervals of 5 $\mathrm{mm}$, while preserving both vertical fibres and the penetrating blood vessels from the pia. This results in reduction of the synchronised discharge from the epileptic focus and limitation of its spread without jeopardising the function of cerebral cortex. The procedure has been effective in controlling seizures without producing major postoperative neurological deficit.

\section{Materials and methods}

Among the 288 patients admitted the neurosurgical unit of the Maudsley Hospital for surgery for epilepsy from 1989 to mid-1993, 21 were found to be unfit for exclusively resective procedures as the epileptic zone was in a vital area of the cortex. They were subjected to MST with the procedure described by Morrell et al. ${ }^{2}$ All the patients had detailed clinical, neurophysiological, and neuroradiological assessment before surgery.

All operations were performed under general anaesthesia with an appropriately placed craniotomy determined by prior investigations. In nine patients this entailed reopening a craniotomy made for previous placement of subdural mat electrodes. Six patients underwent biopsy-four from the precentral region and two from the postcentral region. Twelve other patients underwent brain resection either of a non-eloquent area of electrically active brain or of an area with an abnormality seen on imaging. Four frontal and seven parietal resections were made in these patients, and one patient underwent resection in both areas. Three patients with the LandauKleffner syndrome had neither resection nor biopsy. The area to be transected was determined in part by previous subacute subdural recordings in nine patients, but mainly by acute electrocorticography (ECoG) at surgery. The transected area involved the precentral and postcentral regions in 13 patients, and extended into the posterior temporal region in four of these. Transection was performed in the left temporal and suprasylvian 
Table 1 Preoperative clinical features of patients treated with MST

\begin{tabular}{|c|c|c|c|c|c|c|}
\hline \multirow[b]{2}{*}{$\operatorname{Age}(y) / \operatorname{sex}$} & \multirow[b]{2}{*}{ Seizure type } & \multirow[b]{2}{*}{$\operatorname{Duration}(y)$} & \multirow[b]{2}{*}{ Frequency } & \multicolumn{2}{|l|}{ Neurological deficit } & \multirow[b]{2}{*}{ Diagnosis } \\
\hline & & & & Preoperative & Postoperative & \\
\hline \multicolumn{7}{|c|}{ Group I: $M S T$ and resection } \\
\hline $15 / F$ & $\begin{array}{l}\text { Left partial motor } \\
\text { with generalisation }\end{array}$ & 15 & 2-3/day & Left hemiparesis & Improved & Cortical dysplasia \\
\hline $47 / M$ & $\begin{array}{l}\text { Left partial sensori- } \\
\text { motor with } \\
\text { generalisation }\end{array}$ & 42 & 3-8/day & None & Left hemiparesis & Cortical dysplasia \\
\hline $\begin{array}{l}8 / M \\
\text { 9/M }\end{array}$ & $\begin{array}{l}\text { Left partial sensorimotor } \\
\text { Left partial motor } \\
\text { with generalisation }\end{array}$ & $\begin{array}{l}1 \cdot 5 \\
9\end{array}$ & $\begin{array}{l}\text { Status } \\
1-12 / \text { day }\end{array}$ & $\begin{array}{l}\text { Left hemiparesis } \\
\text { Left hemiparesis }\end{array}$ & $\begin{array}{l}\text { Improved } \\
\text { Improved }\end{array}$ & $\begin{array}{l}\text { Rasmussen's syndrome } \\
\text { Cortical dysplasia }\end{array}$ \\
\hline $26 / F$ & $\begin{array}{l}\text { Left partial sensori- } \\
\text { motor with generalisation }\end{array}$ & 10 & Status & Left hemiparesis & Left hemiparesis & Rasmussen's syndrome \\
\hline $\begin{array}{l}8 / \mathrm{F} \\
19 / \mathrm{F}\end{array}$ & $\begin{array}{l}\text { Right partial motor } \\
\text { Left partial motor }\end{array}$ & $\begin{array}{r}3 \cdot 5 \\
18 \cdot 5\end{array}$ & $\begin{array}{l}10-20 / \text { day } \\
\text { 4-5/day }\end{array}$ & $\begin{array}{l}\text { None } \\
\text { None }\end{array}$ & $\begin{array}{l}\text { None } \\
\text { None }\end{array}$ & $\begin{array}{l}\text { Non-specific changes } \\
\text { Cortical dysplasia }\end{array}$ \\
\hline $29 / \mathrm{F}$ & $\begin{array}{l}\text { Right partial sensorimotor } \\
\text { with generalisation }\end{array}$ & 19 & 3-12/day & None & $\begin{array}{l}\text { Mild apraxia } \\
\text { of hand }\end{array}$ & $\begin{array}{l}\text { Gliosis, non- } \\
\text { specific changes }\end{array}$ \\
\hline $8 / F$ & Right partial motor & 0.33 & Status & Right hemiparesis & Improved & Tumour \\
\hline $20 / \mathrm{F}$ & Complex partial & & $2-3 /$ month & None & None & Cortical dysplasia \\
\hline $22 / F$ & Right partial motor & & $10 /$ day & Right hemiparesis & No change & Non-specific changes \\
\hline $12 / \mathrm{F}$ & Right partial motor & 4 & Status & $\begin{array}{l}\text { Right hemiparesis } \\
\text { and dysplasia }\end{array}$ & No change & Rasmussen's syndrome \\
\hline \multicolumn{7}{|c|}{ Group II: MST and Biopsy/MST alone } \\
\hline $14 / F$ & Right partial motor & 5 & 3-4/week & None & None & Rasmussen's syndrome \\
\hline $12 / F$ & Right partial motor & 0.75 & Status & Right hemiparesis & No change & Rasmussen's syndrome \\
\hline $10 / \mathrm{F}$ & Generalised tonic clonic & 5 & 2 in $5 y$ & $\begin{array}{l}\text { Aphasia, behaviour } \\
\text { disorder }\end{array}$ & Speech recovered & Labdau-Kleffner syndrome \\
\hline $19 / \mathrm{F}$ & Right partial motor & 8 & Status & Right hemiparesis & Improved & Rasmussen's syndrome \\
\hline $14 / \mathrm{M}$ & Generalised tonic clonic & 3 & 3 in $3 y r$ & Aphasia & Speech recovered & Landau-Kleffner syndrome \\
\hline $16 / \mathrm{F}$ & Right partial motor & 6 & 2-3/day & None & None & Non-specific changes \\
\hline $14 / \mathrm{F}$ & Right partial motor & 4 & 5-10/month & None & None & Non-specific changes \\
\hline $6 / \mathrm{F}$ & Left partial motor & 5 & 2/day & Left hemiparesis & No change & Cortical dysplasia \\
\hline $8 / \mathbf{M}$ & Tonic-clonic & 4 & $2 / y$ & Aphasia & Speech recovered & Landau-Kleffner syndrome \\
\hline
\end{tabular}

area in two patients. Precentral, postcentral, frontal, parietal, left temporal, and combined frontal, precentral, and central transections were carried out in one patient each.

\section{Results}

\section{CLINICAL FEATURES}

Multiple subpial transection was carried out on 21 (five male, 16 female) patients. Their age range was 6 to 47 (mean 15.9) years. Eighteen patients presented with medically intractable seizures, of whom six had recur-

Table 2 ECoG findings during MST

\begin{tabular}{|c|c|c|c|c|c|}
\hline \multirow[b]{2}{*}{ Site } & \multirow[b]{2}{*}{$\begin{array}{l}\text { Discharges/ } \\
10 s\end{array}$} & \multirow[b]{2}{*}{$\begin{array}{l}\text { Extent } \\
\text { of } M S T\end{array}$} & \multicolumn{2}{|c|}{ Discharges post-MST } & \multirow[b]{2}{*}{ Outcome } \\
\hline & & & $\begin{array}{l}\text { Ratel } \\
10 s\end{array}$ & $\begin{array}{l}\text { \% of } \\
\text { Previous }\end{array}$ & \\
\hline \multicolumn{6}{|c|}{ Group I: $M S T$ and resection } \\
\hline CPF & $>20$ & Subtotal & $>10$ & 50 & Unimproved \\
\hline C & 4-10 & Total & $1-3$ & $<10$ & Improved \\
\hline C & $>10$ & Total & 0 & 0 & Unimproved \\
\hline $\mathbf{C P}$ & $<1$ & Total & $<1$ & - & Improved \\
\hline CP & $4-10$ & Total & $1-3$ & $<10$ & Improved \\
\hline $\mathrm{CP}$ & \multicolumn{4}{|c|}{ - (technically inadequate ECoG) - } & Improved \\
\hline FCP & $>10$ & Total & 1-3 & $<10$ & Improved \\
\hline $\mathrm{CP}$ & $>10$ & Subtotal & $<1$ & $<10$ & Improved \\
\hline $\mathbf{P}$ & $>10$ & Total & $>10$ & $>200$ & Unimproved \\
\hline CP & $>10$ & Total & 0 & 0 & Improved \\
\hline PT & $>10$ & Total & $1-3$ & $<10$ & Improved \\
\hline PT & $>10$ & Total & 4-10 & $<50$ & Improved ${ }^{\star}$ \\
\hline \multirow{10}{*}{$\begin{array}{l}\text { FP } \\
\text { FCPT } \\
\text { FPT } \\
\text { FPT } \\
\text { FCP } \\
\text { CPT } \\
\text { F } \\
\text { P } \\
\text { T }\end{array}$} & \multicolumn{4}{|c|}{ Group 2: MST and biopsy/MST alone } & \\
\hline & $4-10$ & Total & 4-10 & 50 & Unimproved \\
\hline & $>10$ & Subtotal & $>20$ & 200 & Unimproved \\
\hline & $>10$ & Subtotal & 4-10 & 50 & Improved \\
\hline & $>10$ & Total & $1-3$ & $<10$ & Improved \\
\hline & $>10$ & Subtotal & $>10$ & 50 & Improved \\
\hline & $>10$ & Subtotal & $1-3$ & $<10$ & Improved \\
\hline & $4-10$ & Total & $<1$ & & Unimproved \\
\hline & $>10$ & Total & $>10$ & 100 & Unimproved ${ }^{\star}$ \\
\hline & $>10$ & Total & $>10$ & 200 & Improved $^{\star}$ \\
\hline
\end{tabular}

Sites of discharge: $\mathrm{F}=$ frontal; $\mathrm{C}=$ central; $\mathrm{P}=$ parietal; $\mathrm{T}=$ temporal.

Outcome improved $=$ Sustained control of status epilepticus, or recovery of speech in LandauKleffner syndrome, or seizure reduction grades I or II, ${ }^{1}$ or seizure reduction grade III with decreased severity. Extent of MST: total = entire non-resected discharging area transected; subtotal $=$ non-resected discharging area incompletely transected.

$\star$ Follow up $<12$ but $>10$ months. ring partial status epilepticus or epilepsia partialis continua, which was present on admission. Three patients had Landau-Kleffner syndrome, with global aphasia and an associated behavioural disorder. Table 1 gives the clinical details. For purposes of analysis the patients are divided into two groups. Group I (12 patients) underwent resection of non-eloquent areas supplemented by MST of regions that could not safely be excised. Group II comprised nine patients in whom MST was the primary procedure, resection being confined to a diagnostic biopsy (in six) or not performed (in the three patients with Landau-Kleffner syndrome). The duration of epilepsy ranged from 0.33 to 42 (mean 8.6 ) years.

\section{RADIOLOGY}

Preoperative CT was normal in 16 patients, showed atrophic lesions in three patients, and a calcified lesion suggestive of cortical dysplasia in one. The patients with atrophic lesions had Rasmussen's syndrome. One patient had a cortical defect due to previous incomplete resection of a low grade glioma.

Brain MRI was performed in 17 patients. It was normal in eight, showed cerebral hemiatrophy in four, and focal cortical abnormality in a further five. All the patients with cerebral hemiatrophy had Rasmussen's syndrome and the focal cortical lesions proved to be cortical dysplasia.

\section{THERAPEUTIC OUTCOME OF SURGERY}

(TABLE 2)

One to five years follow up is available in 18 patients, 10 months only in three. Conventional methods of assessing outcome of surgery for epilepsy ${ }^{1}$ hardly seemed appropriate to this group. In the six patients 
Table 3 ECoG and seizure control after MST

\begin{tabular}{|c|c|c|c|c|c|c|}
\hline \multirow[b]{2}{*}{ Outcome } & \multicolumn{2}{|c|}{ Discharge rate pre-MST } & \multicolumn{4}{|c|}{$\%$ Previous rate post-MST } \\
\hline & $\leqslant 10 / \mathrm{s}$ & $>10 / \mathrm{s}$ & 0 & $<10$ & $10-100$ & $>100$ \\
\hline $\begin{array}{l}\text { Improved } \\
\text { Unimproved }\end{array}$ & $\begin{array}{l}3 \\
2\end{array}$ & $\begin{array}{r}11 \\
4\end{array}$ & $\begin{array}{l}1 \\
1\end{array}$ & $\begin{array}{l}7 \\
1\end{array}$ & $\begin{array}{l}3 \\
3\end{array}$ & $\begin{array}{l}1 \\
2\end{array}$ \\
\hline
\end{tabular}

Missing data: No ECoG in one patient due to technical problems; discharge rates pre-MST and post-MST were too low for meaningful comparison in one patient.

with recurrent intractable status epilepticus, sustained abolition of this for at least one year was regarded as an improvement, and was achieved in three, although none became seizure free. The patients with LandauKleffner syndrome had few preoperative seizures; two have had no further attacks, but the criterion of improvement was considered to be recovery of communication skills, which has to some degree been achieved in all three. In the remaining 12 patients, a grade I or II reduction in seizures according to Engel's rating scale ${ }^{1}$ was achieved in five. Three others with a lesser (grade III) reduction in frequency of seizures also experienced a pronounced reduction in seizure severity, which was considered to give a worthwhile improvement in quality of life. No meaningful comparison of outcomes can be made between groups I and II, as there were clinical differences determining the surgical procedure employed. There is, however, no apparent difference in results with respect to seizure control.

The six patients with Rasmussen's syndrome had been subjected to MST rather than hemispherectomy because, although there was an urgent need to control seizures or status epilepticus, there was useful residual function in the hemiparetic limbs. Three patients showed a worthwhile improvement. One of these relapsed briefly with increased seizures after 18 months, but then underwent a further remission that continues. The frequency of seizures remained unchanged in two patients with Rasmussen's syndrome and increased in another; two have now undergone hemispherectomy and are seizure free (a result that is not included in the outcomes shown in table 2).

The progress of the children with LandauKleffner syndrome has been varied. Before operation, all were mute, unresponsive to speech or gesture, and had abandoned even the use of signing. One child was using a few words within 48 hours of surgery and was producing simple, complete sentences within two weeks. A second had made a full recovery of social function and had fluent use of language but still required speech therapy at 30 months (case B later). In the third, progress has been slow but continues after 18 months: improvement in behaviour, comprehension of speech attention, and concentration has been good and is regarded by the parents as sufficient justification for the operation. The patient does now attempt to communicate, which was not so preoperatively, but speech remains limited to single words and articulation is poor; he relies to a considerable extent on signing.
NEUROLOGICAL DEFICIT AND COMPLICATIONS OF SURGERY (TABLE 1)

Of group I, the 12 patients who had resection of the brain in addition to MST, seven were hemiparetic before the operation. All but one of this group developed considerable neurological deficit or worsening of existing hemiplegia in the immediate postoperative period. On follow up the deficits resolved and only two patients had worse function than before the operation.

In group II, six patients underwent brain biopsy in addition to MST and three had MST only. Of these three had preoperative hemiparesis. There was worsening of the hemiparesis in one patient, which subsequently improved. Three patients developed minimal fresh neurological deficit in the form of weakness of hand grip-one case, dystonia-one case, and hemiparesis-one case, which improved over a few days. In no patient was eventual neurological state inferior to that before operation.

In four patients of group I and one of group II (excluding those with Landau-Kleffner syndrome), all with status epilepticus or multiple seizures daily, the eventual neurological deficit was less than before the operation.

No other complications were related directly to the procedure of MST. Arterial bleeding was encountered in one case and responded to appropriate measures. One patient whose general medical condition had been deteriorating preoperatively due to uncontrollable status epilepticus developed pulmonary embolism on the fourth postoperative day, but made a good recovery.

\section{NEUROPHYSIOLOGY AND OUTCOME}

The preoperative neurophysiological examination included routine EEG, telemetry, and subacute recording with subdural mats in nine patients. The routine wake and sleep EEG lateralised the lesion correctly in 14 patients and located the focus accurately in seven patients only.

Electrocorticography (ECoG) was carried out in 20 patients before and after MST; an adequate ECoG was not obtained in one patient for technical reasons. Table 2 gives the details of ECoG findings and their relation with the outcome of surgery.

Seven patients showed no clinically noticeable improvement. Findings in these patients ranged from a $100 \%$ increase in discharge rate, through a $50 \%$ or $90 \%$ reduction to complete abolition of ECoG discharged after MST. Conversely, failure to reduce the discharges (in four patients), or a reduction of not more than $50 \%$ (in four) was not incompatible with improvement, which occurred in five of these eight instances. Complete transection of the non-resected area of ECoG discharge was not feasible when the affected area extended on to the medial aspect of the hemisphere. Subtotal transection of the discharging area did not preclude clinical improvement, but this was achieved in only three of the six patients who had incomplete transections. 
CASE SUMMARIES

The following case histories illustrate the clinical presentation, ECoG findings, and outcome of surgery in patients treated with MST.

\section{Case A}

This 26 year old woman developed normally until the age of 15 years. From this age she had partial sensorimotor seizures starting from the left side of the body and becoming generalised. Some of the seizures were followed by left hemiparesis. She required multiple admissions for status epilepticus and at times her focal seizures occurred up to 40-50 times a day. In June 1991, examination showed a grade 4 pyramidal weakness of the left side and previous psychological assessment showed a verbal IQ of 79, performance IQ of 67 and impairment of visual memory and spatial orientation suggestive of right parietal damage. The most recent CT showed mild right cerebral atrophy and MRI was reported to be normal. In August 1991, she was admitted to the referring hospital in status epilepticus requiring ventilation. The status was controllable with intravenous propofol, but recurred whenever this was withdrawn. The EEG showed a right frontal focus of epileptiform activity.

The subdural recordings confirmed that seizure activity started from right frontal and centroparietal areas. She had a frontal lobectomy, parietal resection, and MST of the central area. Postoperatively she required high doses of propofol to stop focal seizures. Her left sided weakness was initially much worse and her conscious level was clouded. Changing her to intravenous chlormethiazole stopped the seizures and she gradually became more alert.

Ten days postoperatively, she was off all intravenous treatment and was taking $60 \mathrm{mg}$ phenobarbitone, $300 \mathrm{mg}$ phenytoin, and $3 \mathrm{~g}$ sodium valproate per day. On transfer back to the referring hospital her hemiparesis was improving. The pathology was of Rasmussen's encephalitis.

At six months she was walking with assistance and living in a sheltered environment. She has had four tonic-clonic seizures and experiences two to three focal seizures a day affecting the left limbs, during which she understands what is going on but cannot communicate. Her emotional state is also much more stable. On review at one year, she had had no further generalised seizures. She had continued to experience left sided focal seizures, but these no longer occurred every day. They did not interfere with her life except on two occasions when she had a run of focal seizures associated with an intercurrent illness.

\section{Case B}

This 10 year old girl developed normally until 5 years of age. Then her parents noticed that she would often simply stare after being given instructions. She began to mispronounce words, draw objects she wanted, and began to use hand gestures. At the age of 8 (1990) she developed seizures, which consisted of tonicclonic movements of the right limbs, and flickering of the right eye. Investigations at this time showed bitemporal abnormalities on EEG and normal CT, MRI, and SPECT. The diagnosis of Landau-Kleffner syndrome was made. Over the next two years her behaviour became difficult, she tried to injure herself and others and changed her sleeping habits. By March 1992, she was totally aphasic. She neither used nor responded to gesture and seemed incapable of any social interaction. The EEG showed both generalised and independent right and left temporal discharges. Electrical status epilepticus was present in slow wave sleep. Intracarotid sodium amytal and thiopentone suppression tests confirmed the left side as the origin of the seizures. A left craniotomy with electrocorticography and extensive MST were carried out in the precentral gyrus, sylvian area, and posterior temporal and parietal lobes. Postoperatively she experienced right sided focal twitching with some mild weakness of the right hand. After three weeks her hand returned to normal and she was discharged taking sodium valproate $(1 \cdot 1 \mathrm{~g})$ daily.

At three months her behaviour had improved as had her sleeping. She was able to pronounce 35-40 words and produce sentences of up to five words. She supplemented her limited speech by signing. Her verbal comprehension was good. A wake and sleep EEG was performed six months after the surgery and the only abnormality was an occasional right temporal spike discharge. After this she was gradually taken off sodium valproate. She had a vocabulary of 300 words, stringing together six word sentences by nine months. There was improvement in receptive language and behaviour. She had a generalised seizure and postictal right hemiparesis lasting for a few hours one year after the surgery, but there have been no seizures in the past 18 months. A further sleep EEG was performed and persistent epileptiform activity was now absent during sleep. After two years follow up improvement continued in respect of language and behaviour. She still had some difficulty pronouncing " $d$ " and "g" and made some syntactic errors. She was reported to be among the most socially skilled of her class and worked with enthusiasm at her speech therapy.

\section{Discussion}

Experimental data show that the major thalamocortical connections have a trajectory perpendicular to the cortical surface and the vertical column is a master organisation principle of the cerebral cortex..$^{5-8}$ Most of the cortical interneurons in the sensorimotor cortex relay information in a vertical cascade synapsing with apical dendrites of pyramidal cells. Further experiments in cats have shown that surgical cross hatching of the visual cortex or implantation of mica plates did not impair visual perception. ${ }^{910}$ These findings confirm that most of the cortical connections 
responsible for cerebral function lie in the vertical columns. If vertical columns are preserved the horizontal fibres can be severed without producing much functional deficit. This forms the basis of MST.

The paroxysmal depolarisation shift (PDS) is a common feature in many animal models of focal epilepsy. ${ }^{11-13}$ It is a prolonged depolarisation recorded intracellularly and accompanied by high frequency firing associated with interictal spikes on a surface EEG. Paroxysmal depolarisation shifts can be recorded from many cells in an epileptic focus in relation to surface spikes. This implies that an extensive synchronisation of several epileptic neurons is necessary to create an epileptiform field potential. The epileptic neurons do not exhibit an abnormality of resting potential when measured at the level of cell soma. ${ }^{14}{ }^{15}$

The fractional spikes are thought to arise from dendrites ${ }^{1617}$ and it is suggested that some membrane anomaly may exist and it may be mediated by side to side interactions among dendrites in superficial cortical laminae. ${ }^{18} \mathrm{~A}$ burst in a single epileptic neuron does not constitute a propagating epileptic discharge, which requires synchronous activity of many neurons. The minimum volume essential to sustain synchronous spiking has been empirically determined to be $12.5 \mathrm{~mm}^{3} .1920$ Cortical islands greater than $5 \mathrm{~mm}^{3}$ can support paroxysmal discharge. ${ }^{19-23}$ This is the rationale of making transections at $5 \mathrm{~mm}$ intervals.

The success of MST can be assessed from two aspects: control of seizures and postoperative functional neurological deficit. Morrell $e t$ al evaluated the effect of MST on neurological function in 32 cases. $^{2}$ Multiple subpial transection was applied to the precentral gyrus in six patients, Broca's area in five, and Wernicke's area in five. Although subtle deficits could be detected by careful neurological examination none of the patients had significant behavioural or motor deficit. On follow up of more than five years, 11 out of 20 cases were completely free of seizures. Nine patients developed recurrent seizures consequent to a progressive disease. In none of these cases did the recurrent seizures arise from the transected area. Shimizu et al treated 12 patients with intractable epilepsy with MST. ${ }^{4}$ The results proved that MST was effective in controlling the seizures without producing explicit neurological deficit. The limited follow up in this series showed that there was a significant decrease in seizure frequency in five out of nine cases. Three out of these five cases had brain resection of the epileptic zone along with MST. The isolated effect of MST in controlling the seizure frequency was difficult to assess because of the few cases and the associated resection procedure. The preliminary findings suggested that the procedure was helpful in decreasing the seizure frequency. Three patients were helped by MST as it limited the seizure spread.

The evaluation of functional deficit due to MST was difficult in the present series as 12 out of 21 patients had brain resection in addi- tion to MST and preoperative neurological deficit (excluding the dysphasia of the Landau-Kleffner syndrome) was present in 10 . Of the patients who underwent brain biopsy or MST only (group II; $n=9$ ), none had any sustained deterioration of neurological state. Among the 12 in whom resections were performed two had lasting neurological deterioration, severe in one. These results are consistent with findings reported earlier. In five patients the eventual neurological deficit was less than before surgery, the result probably of the relief of status epilepticus or very frequent seizures producing functional deficits.

Patients with Rasmussen's syndrome generally need major resections or hemispherectomy for control of seizures. ${ }^{24} \mathrm{Hemi}$ spherectomy, however, may be hard to justify, or indeed refused by the patient and relatives, if there is no severe neurological deficit. An intractable preoperative status epilepticus or epilepsia partialis continua was present in five of our six patients with Rasmussen's syndrome, and was temporarily controlled after MST in four. Three of the six patients had good long term seizure control, although one of them relapsed briefly after 18 months. The limited favourable experience with this procedure shows that it may have a role in the management of patients of Rasmussen's syndrome with mild neurological deficit. It remains to be determined whether there is any advantage in postponing by MST an eventual hemispherectomy in those patients in whom the condition continues to progress.

It seems logical that a functional operation intended to abolish epileptic discharges should be conducted under ECoG control. In the event the value of ECoG seems limited. Improved seizure control was more likely in those patients with a high initial discharge rate and a $90 \%$ reduction in discharges after MST (table 3), but these trends were weak and not statistically significant. An ECoG was used to determine the site of MST in all but two cases, and where possible transection was extended or repeated in areas of residual discharge; thus the present findings represent the outcome of ECoG guided MST. It would not therefore be justifiable to assume that similar results would have been obtained without ECoG and that the procedure served no useful purpose. A prospective controlled study to obtain reliable evidence of the utility of ECoG during MST is desirable but likely to present considerable methodological problems.

Multiple subpial transection may be effective for relief of intractable seizures and particularly for terminating prolonged, medically uncontrollable partial motor status epilepticus. It does not lead to major neurological deficit. It is the procedure of choice when the epileptic focus is in one of the eloquent areas of the cortex, and may be worth consideration in other cortical areas when the underlying pathology does not demand resection.

IMSS is a Commonwealth Medical Fellow. 
1 Engel J. Outcome with respect to epileptic seizures. In: Engel J. ed. Surgical treatment of the epilepsies. Raven Press, New York. 1987:553-71.

2 Morrell F, Walter WW, Bleck TP. Multiple subpial transection: a new approach to the surgical treatment of section: a new approach to the surgical
focal epilepsy. $₹$ Neurosurg 1989;70:231-9.

3 Dogali M, Devensky O, Luciano D, Perrine K, Beric A Experiences with multiple subpial cortical transections for control of intractable epilepsy in exquisite cortex. Acta Neurochirurgica 1992;117:108.

4 Shimizu H, Suzuki I, Ischijima B, Karasawa S, Sakuma T Multiple subpial transection (MST) for the control of seizures that originated in unresectable cortical foci. f Psychiatry Neurol 1991;45:354-6.

5 Asanuma $\mathrm{H}$. Recent developments in the study of the columnar arrangement of neurons within the motor cortex. Physiol Rev 1975;55:143-56.

6 Asanuma H, Sakuta H. Functional organisation of cortical afferent system combined with focal depth stimulation in cats. $\mathcal{f}$ Neurophysiol 1967;30:35-54.

7 Asanuma H, Stoney SD Jr, Abzuge C. Relationship between afferent input and motor outflow in cat motorsensory cortex. F Neurophysiol 1968;31:670-81.

8 Hubel DH, Wiesel TN. Receptive fields binocular interaction and functional architecture in the cats' visual cortex. F Physiol 1962;160:106-54.

9 Sperry RW, Miner N. Pattern perception following insertion of mica plates into visual cortex. $\mathcal{f}$ Comp Physio Psychol 1955;48:463-9.

10 Sperry RW, Miner N, Myers RE. Visual pattern perception following subpial splicing and tantalum wire implantations in visual cortex. F Comp Physiol Psychol 1955;48:50-8.

11 Matsumoto H, Ajmone Marsan C. Cortical cellular phenomena in experimental epilepsy: interictal manifestanomena in experimental epilepsy:

12 Matsumoto $\mathrm{H}$, Ajmone Marsan C. Cortical cellular phenomena in experimental epilepsy: ictal manifestations. Exp Neurol 1964;9:305-26.

13 Walden J, Straub H, Speckmann EJ. Epileptogenesis: con- tribution of calcium ions and anti-epileptic calcium antagonists. Acta Neurologica Scandinavica 1992;140 (suppl 86):41-50

14 Ayala GF, Dichter M, Gumnit RJ, et al Genesis of interictal spikes. New knowledge of cortical feedback systems suggests a neurophysiological explanation of brief paroxsuggests a neurophysiological

15 Dichter M, Ayala GF. Cellular mechanisms of epilepsy: a status report. Science 1987;237:157-64.

16 Pumain R. Electrophysiological abnormalities in chronic epileptogenic foci: an intracellular study. Brain Res 1981;219:445-50.

17 Wong RKS, Prince DA, Basbaum AL. Intradendritic recordings from hippocampal neurons. Proc Natl Acad Sci USA 1979;76:986-90.

18 Dudel FE, Snow RW, Taylor CP. Role of electrical interactions in synchronizations of epileptiform bursts. In: Delgado-Escueta AV, Ward AA Jr, Woodbury DW, et al, eds. Basic mechanisms of epilepsies. Molecular and cellular approaches. New York: Raven Press 1986: 593-617.

19 Lüders $H$, Bustamente L, Zablow $L$, et al. The independence of closely spaced discrete experimental spike foci. Neurology 1981;31:846-51.

20 Sharp BR. The penicillin focus: a study of field characteristics using cross-correlation analysis. Electroencephalogr Clin Neurophysiol 1971;31:45-55.

21 Dichter M, Spencer WA. Penicillin-induced interictal discharges from the cat hippocampus. I. Characteristics and topographical features. $\mathcal{F}$ Neurophysiol 1969;32:649-62.

22 Dichter M, Spencer WA. Penicillin-induced interictal discharges from cat hippocampus. II. Mechanisms underlying origin and restriction. F Neurophysiol 1969;32: 663-87.

23 Goldensohn ES, Zablow L, Salazar A. The penicillin focus I. Distribution of potential at the cortical surface. I. Distribution of potential at the cortical surface.

24 Honavar M, Janota I, Polkey CE. Rasmussen's encephalitis in surgery for epilepsy. Develop Med Child Neurol 1992; 34:3-14. 